\title{
An audit of patient inclusion in retinopathy of prematurity (ROP) screening and whether discharge summaries contained ROP information with suggestions for improvement
}

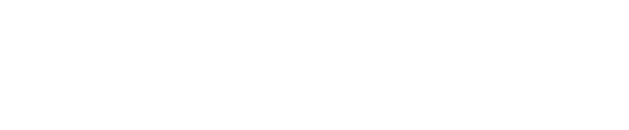

\author{
Samantha A Harding' \\ Mohamad Abdullah ${ }^{1,2}$ \\ Gillian Adams ${ }^{1,2}$ \\ 'Great Ormond Street Hospital for \\ Children, ${ }^{2}$ Moorfields Eye Hospital, \\ London, UK
}

\begin{abstract}
In a busy neonatal unit with a number of very sick children it can be difficult to highlight those children requiring retinopathy of prematurity screening and to include this in the patient's discharge summary to ensure continuity of care. This audit looks at how efficiently children are included in the retinopathy of prematurity (ROP) screening programme at one tertiary referral unit and how well information is recorded in the discharge summary. A total of 185 infants were audited over two, 3-month periods with a sticker system for the notes devised between measurements. Re-audit showed improvement in the numbers included for ROP screening and the frequency with which ROP information was included in the discharge summaries. This simple, low cost system provides an effective method of ensuring optimum care for premature infants with ROP.
\end{abstract}

Keywords: neonatal unit, sticker, discharge summary

\section{Introduction}

Great Ormond Street Hospital (GOSH) is unique in a number of respects. While maintaining a position as probably the most advanced neonatal intensive care unit in the UK, there is no maternity department at the hospital. Therefore patients are received from throughout the country for a variety of reasons such as the need to perform rapid or complex procedures, or the care of extremely ill, very premature patients. As a consequence patients are admitted and discharged from the unit swiftly, with unit staff responsible for the challenging task of identifying infants eligible for retinopathy of prematurity (ROP) screening. The discharge summary is an important tool for ensuring patients with ROP receive continuity of care. Against this background, this audit had two standards:

1. To ensure that all patients coming to the neonatal intensive care unit (NICU) eligible for ROP screening were seen by the ophthalmology team (Audit standard 100 per cent).

2. To ensure all patients leaving the NICU who were eligible for ROP screening had the need for ROP screening noted in the discharge summary (audit standard - 100 per cent). ${ }^{1}$

\section{Method}

The initial audit was conducted over 3 months (October to December 2010) and re-audit was conducted over a further 3-month period (May to July 2011). Every child in the 
unit between these dates was recorded from the admissions record book and patient notes. Only those eligible for ROP screening by the guideline criteria were included in the analysis.

Between initial audit and re-audit, the following changes were identified and implemented:

1. A method to highlight which patients required ROP screening: a sticker was devised to highlight the patients requiring ROP screening (Figure 1) and incorporated into a rubber stamp (Figure 2).

2. A reminder to NICU staff that the discharge summary should contain some reference to ROP where necessary.

The sticker was placed at the inside front cover of the patient's notes and within the patient's notes.

The secretarial staff in the department instructed all newly inducted registrars on the need to include ROP in the discharge summary and a heading for ophthalmology was included in the discharge summary template. The above measures were put in place prior to the re-audit.

ROP ward rounds were regularly carried out once a week on the unit on Wednesdays between 07:30 and 09:00 AM.

\section{Results}

In the initial 3-month audit, 97 children were admitted to the unit. Of these, 26 were identified as eligible for review by the UK guidelines gestational age and weight criteria (31 weeks and 6 days and $<1501 \mathrm{~g}$ ). ${ }^{1}$ Two of these children returned to the NICU on two separate occasions making a total of 28 admissions or episodes by weight and age eligible for ROP screening.

Of these 28 episodes ( 26 children) 8 children ( 9 episodes) were seen and 18 children (19 episodes) were not (see Table 1).

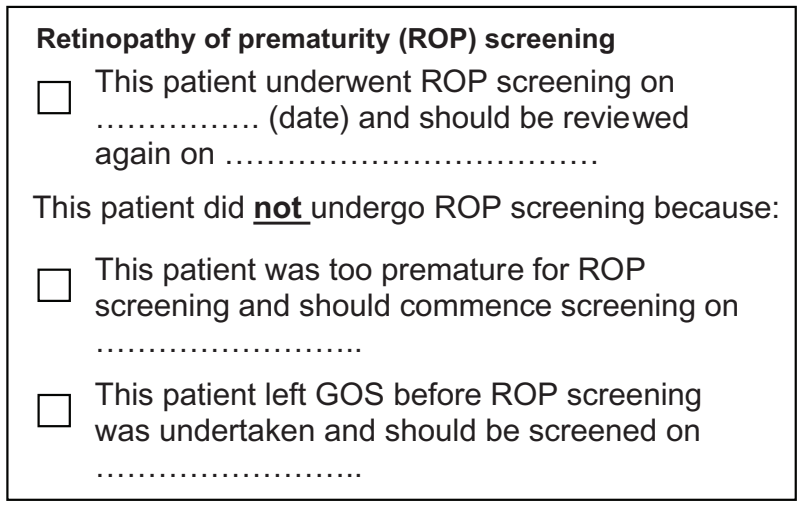

Figure I The retinopathy of prematurity (ROP) sticker design devised for incorporation into a stamp.

Abbreviation: GOS, Great Ormond Street.

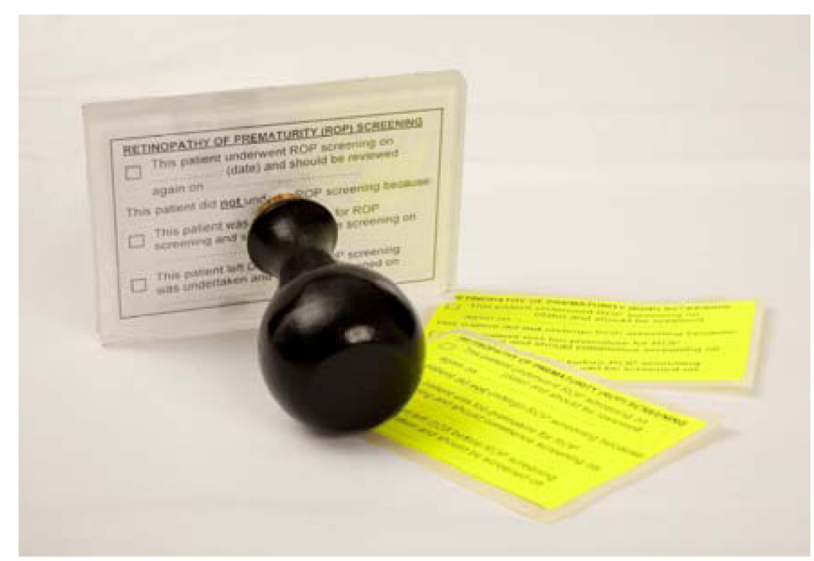

Figure 2 The retinopathy of prematurity sticker incorporated into a stamp and placed on a bright yellow sticker.

Of those not seen, the distribution of reasons for failure to undergo review is shown in Table 2.

One child seen on two separate occasions was too premature to review on the first and off the unit on the second occasion and therefore appears in two "not seen" categories.

Excluding children too premature, discharged before review, off the unit, and outside the criteria, a total of 12 children were eligible for review and 8 were seen $(67 \%$ : see Table 1).

At the re-audit, 92 admission episodes (88 infants) were recorded during this period and only those eligible for ROP screening were analysed. Twenty-five children (29 episodes) admitted during this period came under the eligibility criteria for ROP screening. One child was admitted and discharged three times and three children were admitted and discharged twice, making up this total.

Table I Summary of patients included in the audit and re-audit phases (admission episodes in brackets)

\begin{tabular}{|c|c|c|}
\hline & First audit & Re-audit \\
\hline Total number of infants included & 97 infants (99) & 88 infants (92) \\
\hline $\begin{array}{l}\text { Total eligible for ROP screening } \\
\text { by age and weight criteria } \\
\text { ( } 31 \text { days and } 6 \text { weeks } / 40,<1501 \mathrm{~g} \text { ) }\end{array}$ & 26 infants (28) & 25 infants (29) \\
\hline $\begin{array}{l}\text { Total number of infants eligible } \\
\text { for ROP screening omitting } \\
\text { those not seen }\end{array}$ & 12 & 15 \\
\hline $\begin{array}{l}\text { Total number of infants } \\
\text { actually seen }\end{array}$ & 8 infants $(9,67 \%)$ & $\begin{array}{l}12 \text { infants } \\
(12,80 \%)\end{array}$ \\
\hline Infants not seen & 18 infants (19) & I5 infants (I7) \\
\hline $\begin{array}{l}\text { Total number of discharge } \\
\text { summaries collected }\end{array}$ & 25 (89.2\%) & $21(72.4 \%)$ \\
\hline $\begin{array}{l}\text { Total number of discharge } \\
\text { summaries mentioning ROP }\end{array}$ & 0 & $8(38 \%)$ \\
\hline
\end{tabular}

Abbreviation: ROP, retinopathy of prematurity. 
Table 2 Distribution of reasons why children were not seen by episode

\begin{tabular}{lll}
\hline & First audit & Re-audit \\
\hline Total not seen & 18 children & 15 children \\
& 19 episodes & 17 episodes \\
$\begin{array}{l}\text { Too premature } \\
\text { Patient outside UK guideline } \\
\text { criteria at time of admission }\end{array}$ & 2 & 7 \\
$\begin{array}{l}\text { Discharged before review } \\
\text { could take place }\end{array}$ & 2 & 0 \\
$\begin{array}{l}\text { Off unit } \\
\text { Deceased }\end{array}$ & 2 & 4 \\
Unrecorded & 0 & 1 \\
\hline
\end{tabular}

Of these, 12 children (12 episodes) were seen and 15 children (17 episodes) were not (see Table 1).

Of those not seen, reasons for this are shown in Table 2. One infant was not seen as on the first occasion he was off the unit and the second discharged before review, and therefore features in two separate "not seen" categories.

Excluding those too premature, discharged before review, off the unit and the deceased child, 15 children in total could have been seen and only 12 were $(80 \%$ - see Table 1).

\section{Analysis of discharge summaries}

Every individual visit to the NICU generated a discharge summary kept on the departmental computer hard drive, therefore analysis of discharge summaries was performed per episode or admission. Of the 26 children (28 episodes) eligible for ROP screening, discharge summaries were obtained for 25 of the children ( 25 episodes, $89.3 \%$ ). The discharge summaries were surveyed for any mention of ROP screening. None of the discharge summaries contained any mention of ROP screening $(0 \%)$.

Following re-audit, of the 29 episodes ( 25 children), 21 discharge summaries (17 children) were obtained (72.4\%). Of these, 8 mentioned ROP screening (38\%). The distribution of stickers on the front and within the notes was analysed by the number of notes only and not by episodes as each child had a single set of notes, regardless of the number of admission and discharge episodes. Of the 25 children eligible for ROP screening, 21 sets of notes were obtained (84\%). Fourteen $(67 \%)$ had stickers on the front of their notes and $10(48 \%)$ had stickers within the notes. Six children (29\%) had both. In two cases where no sticker was affixed at all, mention was nevertheless made of ROP in the discharge summary. In five cases where stickers were affixed, three on both the front and in the notes and two on the front only, no mention was made of ROP in the discharge summary.

\section{Discussion}

The high levels of throughput of patients, some in the unit for just 4 hours and arriving during the night, meant that the ophthalmology team was completely reliant on the NICU staff to advise them on the presence of children eligible for ROP screening. The majority of babies not seen in both loops of the audit came into the "too premature" category. Gestational ages ranged from 23 weeks and 1 day to 31 weeks and 4 days (with one child at 42 weeks and 0 days but a weight of $890 \mathrm{~g}$ ). In one case when a child was seen erroneously at only 27 weeks, the cloudy cornea obscured the retinal view. It is likely, therefore, that any attempt to seize the opportunity to see children in the unit regardless of gestational age in order to ensure that they are, indeed, seen, would be fruitless.

The percentage of children seen, reaching only $80 \%$ in the re-audit, although falling well below the standard set in the guidelines, is probably around the norm for this unusual unit. With almost 200 infants passing through the unit during the 6 months covered by the two loops of the audit, the high throughput, extreme prematurity, and need to undergo procedures that characterize these infants would make it very difficult to increase this percentage. Therefore, the discharge summary information becomes a most important source of passing on the need for ROP screening to receiving units on discharge.

The introduction of brightly coloured, prominently placed stickers in the patients' notes had unexpected effects. They served to make all staff "ROP aware" so that, even in children without stickers, the need to undergo ROP screening and record ROP information in the discharge summary was recognized. The ophthalmology team could use the stickers to highlight the need for ROP screening, and the need for inclusion in the discharge summary, to NICU staff. NICU secretarial staff also encouraged the NICU staff to include ROP in the discharge summary and there was a gratifying, though modest, rise in the number of children having ROP mentioned in their discharge summaries. With children being discharged to up to 13 different UK hospitals, concise statements of the ROP status in the discharge summary were crucial.

There remains considerable scope for improvement. Further remedial steps could include seminars to NICU staff detailing the importance of ROP screening and dealing with any difficulties non-ophthalmic staff may have around implementation. One could further envisage a role for computerized alert systems and electronic patient records 
in bringing about improvements. Such changes could occur alongside possible remodelling of the current system, for example the discussion of ROP on the morning ward round and centralized collation of all new ROP arrivals through a single member of staff.

It is interesting to note that of those children in the second loop who came to the NICU with discharge summaries under the Standardised Electronic Neonatal Database (SEND) system, only $42 \%(8 / 19)$ made any mention of ROP. However, regrettably, of the eight SEND discharge summaries that mentioned ROP, three GOSH discharge summaries failed to make any mention at all of ROP. The GOSH discharge summaries had, therefore, "broken the chain" of information to the next care provider. Conversely, three patients who came with SEND discharge summaries silent on ROP had mention of ROP made in their GOSH discharge summaries. The low percentage of patients coming to the unit without ROP being mentioned at all in the SEND discharge summary correlates with other regional audits. ${ }^{2}$

\section{Conclusion}

The percentage of patients seen from audit to re-audit improved from $67 \%$ to $80 \%$. The number of patients having
ROP mentioned in the discharge summary improved from audit to re-audit from $0 \%$ to $38 \%$.

A sticker was a simple and effective way of attempting to change behaviour and highlight to NICU staff those children requiring ROP screening. This in turn led to increased mention of ROP in the discharge summaries, ensuring greater continuity of care for patients.

\section{Disclosure}

The authors have no interests to disclose in this work.

\section{References}

1. Royal College of Ophthalmologists, Royal College of Paediatrics and Child Health, British Association of Perinatal Medicine and BLISS: Guideline for the Screening and Treatment of Retinopathy of Prematurity. London, May 2008.

2. Ziakas NG, Cottrell DG, Milligan DW, Pennefather PM, Bamashmus MA, Clarke M. Regionalisation of retinopathy of prematurity (ROP) screening improves compliance with guidelines: an audit of ROP screening in the Northern Region of England. Br J Ophthalmol. 2001;85(7):807-810.
Clinical Audit

\section{Publish your work in this journal}

Clinical Audit is an international, peer-reviewed, open access journal focusing on the processes and outcomes of clinical audit in any area of healthcare. All aspects of patient care are addressed within the journal and practitioners from all disciplines are invited to submit their work. Areas covered include: Publication of audits; How an audit has changed practice;

\section{Dovepress}

Practical tips on how to do audits and to avoid pitfalls; How audits have changed patient care; Calls and justifications for new audits. The manuscript management system is completely online and includes a very quick and fair peer-review system, which is all easy to use. Visit http://www.dovepress. com/testimonials.php to read real quotes from published authors. 